\title{
Group Testing for SARS-CoV-2: Forward to the Past?
}

\author{
Koen B. Pouwels ${ }^{1}$. Laurence S. J. Roope ${ }^{1} \cdot$ Adrian Barnett $^{2} \cdot$ David J. Hunter $^{3} \cdot$ Terry M. Nolan $^{4} \cdot$ Philip M. Clarke $^{1,5}(\mathbb{0}$
}

Published online: 28 April 2020

(c) The Author(s) 2020

A key challenge many governments have faced in developing a response to the emergence of severe acute respiratory syndrome coronavirus 2 (SARS-CoV-2) has been constraints in the availability of diagnostic tests. The initial focus has been on case identification [1] to facilitate index case isolation, contact tracing and quarantining-necessary measures to maximise disease suppression. Alongside this there will be an increasing need to monitor the spread of the disease in the community to understand the level of age- and geographyspecific population immunity. The challenges presented by testing for SARS-CoV-2 are as much about manufacturing capacity, economics and resource allocation as epidemiology. Here we examine the case for whether group testing should become a key component of the strategy to combat coronavirus disease 2019 (COVID-19).

Even in the most developed countries, reverse transcription polymerase chain reaction (RT-PCR) testing, which involves swab testing for the virus' genetic material and is currently the standard test, is severely constrained [2,3]. This is due to shortages in key supplies, such as reagents, and a limit to the number of tests that can be performed per day using existing equipment [4]. Though no demonstrably

Koen B. Pouwels and Laurence S. J. Roope are joint "first author", with order determined randomly.

Philip M. Clarke

Philip.Clarke@ndph.ox.ac.uk

1 Health Economics Research Centre, Nuffield Department of Population Health, University of Oxford, Oxford, UK

2 Institute of Health Biomedical Innovation (IHBI), Queensland University of Technology, Brisbane, QLD, Australia

3 Translational Epidemiology Unit, Nuffield Department of Population Health, University of Oxford, Oxford, UK

4 The Peter Doherty Institute for Infection and Immunity, University of Melbourne, Melbourne, VIC, Australia

5 Centre for Health Policy, Melbourne School of Population and Global Health, University of Melbourne, Melbourne, VIC, Australia effective antibody test yet exists, some governments have emphasised mass deployment of such tests as a key element of their strategy. Though still to be adequately tested, the United Kingdom (UK) government, for example, has purchased 3.5 million such tests to be used for key workers, with the hope that they will later become widely available in the community [5].

Low- and middle-income countries (LMICs) typically face even greater constraints to testing resources. A survey of preparedness across African countries indicated that in some countries testing capacity is extremely limited, leaving them ill-equipped to respond to the pandemic [6]. Low-cost, rapid diagnostic tests such as that being developed by The UK's Department for International Development, together with the government of Senegal, may be a vital tool in many LMICs' battle against COVID-19 [7]. Yet, even at that test's proposed cost of just US\$1 [7], the feasibility of wide-scale administration of such tests in Senegal and beyond remains unclear. Even US\$1 is more than $10 \%$ of the annual public per capita health expenditure in nearly half of Sub-Saharan African countries [8], and using human immunodeficiency virus (HIV) PCR tests as a benchmark, costs of US $\$ 10$ for rapid diagnostic tests for SARS-CoV-2 seem feasible [9].

There are good reasons why the World Health Organization has made "test, test, test" its mantra in the fight against COVID-19 [10]. As well as facilitating index case isolation and contact tracing in the early stages, testing for infection enables frontline healthcare and other key workers to safely go to work. Effective antibody tests could enable billions globally to safely return to work from lockdowns much sooner, with enormous economic benefits. Testing is also integral to estimating age- and geography-specific proportions of the immune compartment of the population. For example, serosurveys are crucial to predicting the future behaviour of the virus in the population. This would allow governments to understand the likelihood (and expected size) of future waves of the epidemic, and when it can be expected that sufficient herd immunity will be reached to protect the remainder of the susceptible (yet to be infected) population. Testing is also necessary to understanding the 
value of a vaccine (should one become available), and informing its implementation strategy. For example, a vaccine will be much less valuable if it becomes available only after most of the population have developed immunity. However, if testing indicates that certain geographic regions have lower rates of immunity, then these regions could be prioritised for vaccination.

Going forward, there is a need to expand testing of both infection and population immunity levels. This would help provide an evidence base on COVID-19 trajectory and severity that could inform public health policies [11]. The capacity to undertake widespread community-level testing could help mitigate the risk that a relaxation of the current unprecedented social-distancing restrictions many governments have imposed (e.g. ceasing international passenger movements and school and workplace closures) would produce further outbreaks of SARS-CoV-2, which has been estimated to reduce global gross domestic product by up to $2.5 \%$ per month of lockdown [12].

Given these challenges, how could SARS-CoV-2 testing capacity be expanded? One possibility is to initially test at group level, an approach first proposed by statistician Robert Dorfman in the context of screening World War 2 army recruits for syphilis [13]. The advantage of group testing is that if the initial test is negative, the entire group can be eliminated, leading to far fewer tests being used for diseases with low prevalence. If instead the initial test is positive, further testing within the group is needed to determine which members are positive. Group testing has subsequently been used mainly to detect a variety of sexually transmitted diseases [14]. Should we be considering the use of group testing for SARS-CoV-2, as has recently been suggested? [15-17]

There are three questions that should be carefully assessed when evaluating whether group testing might be a useful solution to resource constraints that limit the number of individuals that can be tested. First, can more patients be tested with a fixed number of tests using group testing? Second, to what extent does group testing affect the sensitivity and specificity of the test? Third, would group testing cause operational delays that may have adverse consequences?

There is evidence that nasopharyngeal/throat swab specimens could be pooled and tested for the presence of 2009 H1N1 influenza virus using RT-PCR without a clear detrimental effect on sensitivity [18]. As of 7 April 2020, 26\% of specimens have tested positive during the current COVID-19 outbreak [19]. While this is close to the prevalence at which Dorfman group testing becomes less efficient than individual testing (above 30\%) [13], increasing the number of individuals tested using group testing is expected to reduce the pre-test probability sufficiently to make group testing more efficient [13]. Among populations where the risk of being infected by SARS-CoV-2 is lower, such as tests performed among symptom-free individuals not directly exposed to a known case, group testing is expected to be even more efficient, because larger group sizes can be used. Furthermore, other group testing approaches could be considered if the pre-test probability is relatively high, although there is no grouping method that is more efficient than individual testing above $38 \%$ [20].

However, group testing is only a reasonable option if pooling does not clearly reduce the sensitivity of the test. Pooling specimens for group testing may reduce the sensitivity of the test due to so-called pooling dilution, where an infected specimen is diluted by infection-free specimens, thereby potentially making the infected specimen undetectable. Sensitivity at various group sizes is crucial for determining whether group testing is desirable and for estimating optimal group size. This can be informed by evaluating the effect of pooling one infected specimen with a varying number of uninfected specimens on the sensitivity and cycle threshold $(\mathrm{Ct})$ values $[18,21]$ and mathematical models taking into account viral load progression and dilution effects [22]. Early results from laboratory experiments suggest that a single positive SARS-CoV-2 sample can be detected in pools of up to 32 samples, with an estimated false negative rate of $10 \%$ [16]. With smaller group sizes, additional amplification cycles, or inclusion of a re-test for negative group samples, the false negative rate could be reduced further $[16,23]$.

At low prevalences, group-testing procedures could reduce the number of false negatives and false positives compared with individual testing [23]. The optimal testing design and group size (which may indeed be one under certain conditions) ultimately has to be estimated taking resource constraints, pre-test probabilities, expected number of tests and expected false negative and false positive rates into account. It is not clear whether current RT-PCR tests are sufficiently sensitive for group testing, but given the potential gains in efficiency, ascertaining this for both current and future tests should be a priority. Given the global character of pandemics like COVID-19 and the substantial budget constraints in LMICs, group testing could enable testing of patients that would otherwise not be feasible or affordable.

An obvious concern with group testing, followed by retesting with individual specimens in the event of a positive, is that this may cause operational delays and increase the time between specimens being taken and results being received. This will be test- and context-specific and needs to be carefully evaluated. However, because group testing potentially requires fewer tests to be performed, average time delays may actually be reduced, especially in a pandemic setting where laboratories are working at full capacity. For example, a study from France found that, compared with individual testing, pooling deoxyribonucleic acid (DNA) from nasopharyngeal specimens, and retesting positive 
group samples, considerably reduced both the cost and time delays of using RT-PCR for bacterial detection [21].

There may also be community settings in which finding a single positive in a group would have implications for the whole group. For instance, if a single household member is positive, all other household members would currently be advised to self-isolate for 14 days so treating the household as a single pool would not radically alter advice relative to individual testing.

It may be too late to adapt existing rapid SARS-CoV-2 diagnostic self-tests for group testing, but the design phase of future tests should consider the feasibility of one test being used to test all members of a household or workplace. Pooled assay performance is key, and as this will differ from test to test, the development of assays and assessment of their performance in group testing should go hand in hand.

We conclude that group testing has the potential to substantially reduce constraints in availability of diagnostic tests for SARS-CoV-2. In many circumstances, it could enable limited numbers of diagnostic tests to be used more efficiently, testing more patients without increasing operational delays. The sensitivity of existing and future tests at different group sizes therefore deserves urgent consideration. Group testing should be a forethought not an afterthought.

\section{Compliance with Ethical Standards}

Funding The article was funded by the National Institute for Health Research (University of Oxford (NIHR-BRC-1215-20008)).

Conflict of Interest LSJR and PC are supported by the Oxford NIHR Biomedical Research Centre, Oxford. KBP, LSJR, AB, DH, TN and $\mathrm{PC}$ all have no conflicts of interest to report.

Open Access This article is licensed under a Creative Commons Attribution-NonCommercial 4.0 International License, which permits any non-commercial use, sharing, adaptation, distribution and reproduction in any medium or format, as long as you give appropriate credit to the original author(s) and the source, provide a link to the Creative Commons licence, and indicate if changes were made. The images or other third party material in this article are included in the article's Creative Commons licence, unless indicated otherwise in a credit line to the material. If material is not included in the article's Creative Commons licence and your intended use is not permitted by statutory regulation or exceeds the permitted use, you will need to obtain permission directly from the copyright holder.To view a copy of this licence, visit http://creativecommons.org/licenses/by-nc/4.0/.

\section{References}

1. Laboratory testing for coronavirus disease 2019 (COVID-19) in suspected human cases. World Health Organisation: Interim Guidance. 2020. https://apps.who.int/iris/bitstream/handle/10665 /331329/WHO-COVID-19-laboratory-2020.4-eng.pdf. Accessed 3rd Apr 2020.
2. DutchNews.nl article. 26th March 2020. 2020. https://www.dutch news.nl/news/2020/03/roche-urged-to-share-info-with-dutch -corona-test-labs-ftm/. Accessed 8th Apr 2020.

3. The New Yorker article. 16th March 2020. 2020. https://www. newyorker.com/news/news-desk/what-went-wrong-with-coron avirus-testing-in-the-us. Accessed 8th Apr 2020.

4. The Guardian article. $25^{\text {th }}$ March 2020. 2020. https://www.thegu ardian.com/world/2020/mar/25/australian-health-authorities-askuniversities-to-hunt-down-coronavirus-testing-material. Accessed 8th Apr 2020.

5. Iacobucci G. Covid-19: What is the UK's testing strategy? BMJ. 2020;368:m1222.

6. Gilbert M, Pullano G, Pinotti F, Valdano E, Poletto C, Boëlle PY, d'Ortenzio E, Yazdanpanah Y, Eholie SP, Altmann M, Gutierrez B. Preparedness and vulnerability of African countries against importations of COVID-19: a modelling study. Lancet. 2020;395(10227):871-7.

7. United Kingdom Government Press Release, 6th March 2020. 2020. https://www.gov.uk/government/news/pm-announces-newfunding-in-fight-against-spread-of-coronavirus. Accessed 26th Mar 2020.

8. World Bank Databank. 2020. https://data.worldbank.org/indicator/ SH.XPD.GHED.PC.CD?locations=ZG-ZF. Accessed 26th Mar 2020.

9. The Clinton Foundation. HIV/AIDS Diagnostic Pricing Outlook. 2020. https://www.who.int/hiv/topics/treatment/costing_clint on_diagnostic.pdf. Accessed 8th Apr 2020.

10. World Health Organisation Press Conference, 16th March 2020. 2020. Podcast available at: https://www.bbc.co.uk/news/av/world $-51916707 /$ who-head-our-key-message-is-test-test-test. Accessed 3rd Apr 2020.

11. Lipsitch M, Swerdlow DL, Finelli L. Defining the epidemiology of Covid-19—studies needed. N Engl J Med. 2020.

12. Fernandes N. Economic effects of coronavirus outbreak (COVID19) on the world economy. 2020. Available at SSRN 3557504.

13. Dorfman R. The detection of defective members of large populations. Ann Math Stat. 1943;14(4):436-40.

14. Hourfar MK, Themann A, Eickmann M, Puthavathana P, Laue T, Seifried E, Schmidt M. Blood screening for influenza. Emerg Infect Dis. 2007;13(7):1081.

15. Barnett A. If tests for \#covid19 are limited and pre-test probability is low this is an ideal scenario for group testing. 2020. https ://en.wikipedia.org/wiki/Group_testing. Accessed 16 Mar 2020 (tweet).

16. Gollier C, Gossner O. Group testing against Covid-19, mimeo. 2020. https://gossner.me/wp-content/uploads/2020/03/group-testi ng2020-03-30a.pdf. Accessed 8th Apr 2020.

17. Yelin I, Aharony N, Shaer-Tamar E, Argoetti A, Messer E, Berenbaum D, Shafran E, Kuzli A, Gandali N, Hashimshony T, Mandel-Gutfreund Y. Evaluation of COVID-19 RT-qPCR test in multi-sample pools. 2020 (medRxiv).

18. Van TT, Miller J, Warshauer DM, Reisdorf E, Jernigan D, Humes R, Shult PA. Pooling nasopharyngeal/throat swab specimens to increase testing capacity for influenza viruses by PCR. J Clin Microbiol. 2012;50(3):891-6.

19. United Kingdom Government Guidance. 2020. https://www.gov. uk/guidance/coronavirus-covid-19-information-for-the-publi c\#number-of-cases. Accessed 8th Apr 2020.

20. Ungar P. The cutoff point for group testing. Commun Pure Appl Math. 1960;13(1):49-544.

21. Edouard S, Prudent E, Gautret P, Memish ZA, Raoult D. Costeffective pooling of DNA from nasopharyngeal swab samples for large-scale detection of bacteria by real-time PCR. J Clin Microbiol. 2015;53(3):1002-4. 
22. Nguyen NT, Aprahamian H, Bish EK, Bish DR. A methodology for deriving the sensitivity of pooled testing, based on viral load progression and pooling dilution. J Transl Med. 2019;17(1):252.
23. Litvak E, Tu XM, Pagano M. Screening for the presence of a disease by pooling sera samples. J Am Stat Assoc. 1994;89(426):424-34. 